\title{
Psoriasis susceptibility locus in chromosome region 3q21 identified in patients from southwest Sweden
}

\author{
Fredrik Enlund ${ }^{1}$, Lena Samuelsson ${ }^{1}$, Charlotta Enerbäck ${ }^{2}$, Annica Inerot $^{2}$, \\ Jan Wahlström ${ }^{1}$, Maria Yhr ${ }^{1}$, Åsa Torinsson ${ }^{1}$, John Riley ${ }^{3}$, Gunnar Swanbeck ${ }^{2}$ and \\ Tommy Martinsson ${ }^{1}$ \\ ${ }^{1}$ Department of Clinical Genetics, Gothenburg University, Sahlgrenska University Hospital \\ ${ }^{2}$ Department of Dermatology, Gothenburg University, Sahlgrenska University Hospital, Gothenburg, Sweden \\ ${ }^{3}$ Molecular Genetics, Glaxo Wellcome Medicines Research Centre, Stevenage, UK
}

\begin{abstract}
We have performed a pair-wise linkage study in the search for psoriasis susceptibility regions. A preliminary scan was performed on 20 families. In this set we obtained indications of linkage on chromosome 3q21. This region was further investigated using material from a total of 104 families (set 1B) resulting in a non-parametric linkage (NPL) of 1.77. The material was stratified in families whose parental origin is in southwest Sweden (set 1C). A maximum NPL value of 2.77 was obtained in this group. A transmission disequilibrium test (TDT) was performed on the stratified material (set 1C) and a significant $P$ value of 0.005 was obtained, at marker D3S1269. The locus was confirmed with TDT in replicate material consisting of 148 families in which a single member was affected ( $P$ value 0.0007$)$ at marker D3S1551. Thus, we have observed a significant $P$ value using TDT in the vicinity of markers D3S1269/D3S1551, suggesting a novel psoriasis susceptibility region.
\end{abstract}

Keywords: chromosome 3; psoriasis; TDT

\section{Introduction}

Psoriasis is a skin disorder that affects approximately $2-3 \%$ of the population. ${ }^{1,2}$ Red scaly patches affecting the scalp, elbows or knees are a common characteristic. Patients with psoriasis also have increased incidence of arthritis, the prevalence varying in different studies from around $7 \%$ to $30 \%$. $^{3,4}$ The disease may appear early in life, with the most common age at onset around

Correspondence: $\mathrm{T}$ Martinsson, Department of Clinical Genetics, Sahlgrenska University Hospital/East, S-416 85, Gothenburg, Sweden. Tel: + 463134348 03; Fax: + 463184 21 60; E-mail: tommy.marginsson@clingen.gu.se

Received 9 February 1999; revised 13 April 1999; accepted 28 April 1999 puberty, but other peaks are also registered later in life. ${ }^{5,6}$ The genetics of psoriasis have puzzled investigators for many years and several modes of inheritance have been proposed. ${ }^{1,7}$ A multi-factorial inheritance which involves several genes has been suggested $^{8,9}$ but evidence for a major gene has also been proposed. ${ }^{10}$ We have earlier shown in a population genetic study that a recessive mode of inheritance is compatible with distribution among first degree relatives with a high gene frequency. ${ }^{11}$ With a recessive mode and a high gene frequency, a number of families will appear with a pseudo-dominant inheritance, ie one parent homozygous and the other heterozygous, giving a dominant-like inheritance. 
Tomfohrde et $a l^{12}$ reported the first psoriasis susceptibility locus on chromosome $17 \mathrm{q}$ in a few large families. It was compatible with an autosomal dominant model of inheritance. Replication studies have been reported supporting the locus on $17 q,{ }^{13,14}$ whereas other studies fail to confirm it. $^{15,16}$

Matthews et $a l^{17}$ reported a second psoriasis gene location on chromosome $4 \mathrm{q}$ using a dominant model with reduced penetrance. No other study has been able to confirm this locus. ${ }^{13,14,16}$

Two independent genome scans have been carried out by Trembath et al ${ }^{16}$ and Nair et al. ${ }^{13}$ Trembath et al ${ }^{16}$ identified a major susceptibility locus in the HLA region on chromosome $6 \mathrm{p}$. Other potential psoriasis gene loci were also reported on chromosome $2 \mathrm{p}$ and 8q. ${ }^{16}$ At the same time Nair et al ${ }^{13}$ published a genome scan which confirmed the chromosome $6 \mathrm{p}$ locus and suggested two novel candidate regions on chromosome $16 \mathrm{q}$ and 20p. Recently Capon et $a l^{18}$ suggested a new susceptibility region on chromosome region $1 \mathrm{q}$. Thus, most of these other suggested loci have been presented by one group only. Confirmation of other groups' findings of susceptibility regions on chromosomes 4,6 and 17 , using the same family material (set $1 B$ ), has been reported elsewhere. ${ }^{14}$

The HLA region has been thoroughly examined in many studies, and associations with sub-classes of HLA such as B13, Bw57, Cw6 and DR7 have been reported. ${ }^{19-21}$ We have found a strong correlation between the presence of Cw6 and early onset in this family material. ${ }^{22} \mathrm{~A}$ number of studies have shown linkage to the HLA region, ${ }^{13,16,23-25}$ as does our patient material. $^{14}$

In the present study we have performed a pairwise linkage analysis on a limited number of families with the intention of defining regions of interest for further studies. We used family material where both parents were unaffected, so optimising the search for a major recessive gene among psoriasis patients. Suggested susceptibility regions observed in the preliminary study were further investigated in an additional set of families, ie a two-stage approach. The preliminary results indicated a psoriasis susceptibility locus on chromosome $3 \mathrm{q} 21$, which was further investigated in a total of 104 families (set 1B) (153 sib pairs). Linkage disequilibrium was obtained using a Transmission Disequilibrium Test (TDT) ${ }^{26}$ on a sub-set of families originating in southwest Sweden (set 1C), suggesting a population stratification in the Swedish population. These results were confirmed in an additional set of
148 families (set 2) from the same region. We here present data on a novel psoriasis susceptibility locus in the vicinity of marker D3S1269 on chromosome 3q21.

\section{Materials and Methods}

\section{Family Material}

Since the start of the project in 1992 the group has collaborated with the Swedish Psoriasis Association, which has 22000 registered members, all of whom were contacted. In all, 11366 probands were able to give information on the occurrence of psoriasis among parents and siblings. ${ }^{11}$ Figure 1 gives an overview of all patient materials used in the study. Twenty pedigrees were used in an initial pairwise linkage study. In total, 47 families (family set $1 \mathrm{~A}$, with 21 families in which a single member was affected, and 26 in which several members were affected) were used as first confirmation so as
A

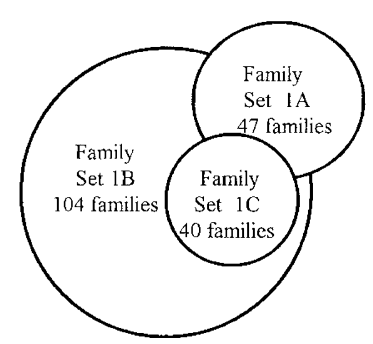

Family set 1A 1B IC
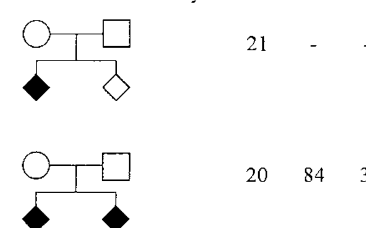

20

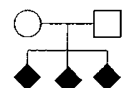

$\square \quad 1 \quad 4 \quad 3(1)$
B
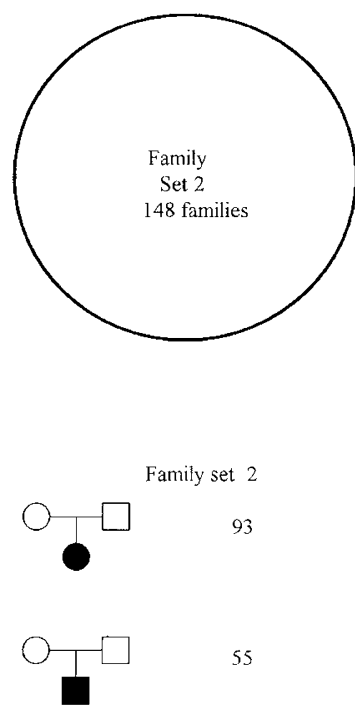

Figure 1 A Family sets used in the linkage studies on chromosome $3 q 21$. Family set $1 A$ was used to verify susceptibility regions in the preliminary genome scan. Family set $1 B$ is the total number of families used to verify the chromosome $3 q 21$ region (including 26 multiply affected families from group 1A). Group 1C (ascertained from 1B) consists of families who originate from southwest Sweden and were used in the association study. Numbers in parentheses indicate families in both sets $1 A$ and 1C. B Families with one affected child originating from southwest Sweden who were used in the replicate TDT study 
to investigate further six suggested regions obtained in the pairwise linkage analysis. Eleven of the 26 'multiple-affected' families from set $1 \mathrm{~A}$ originated in southwest Sweden. The origins of the 'single-affected' families were not recorded. The single-affected families were only used in the first confirmation set in which lod scores were calculated.

For the extended study on the chromosome $3 \mathrm{q}$ location, a total of 104 multiple-affected families (family set 1B) were used (this group include the 26 multiple-affected families (set 1A) used in the confirmation study). The family configuration was 84 families with two affected, 16 families with three affected and four families with four affected children altogether 440 individuals. Only families with two unaffected parents available for genotyping and at least two affected siblings were included in the study. Family members were examined by a dermatologist (AI) and cutaneous sites of involvement were recorded. The severity of the disease was not classified. The medium age of the probands was 41 years, with a lower quartile of 35 and upper quartile of 47 years.

\section{Association Study}

We suspected our material to have a non-homogeneous background due to population stratification in the Swedish population. This hypothesis will be discussed later. Forty multiple-affected families from set 1B that fitted our model, in which at least one parent was born in southwest Sweden (Bohuslän, Halland, Skåne or Blekinge - family set 1C) were reanalysed in an association study on chromosome $3 \mathrm{q} 21$. This cohort consisted of 31 families with two affected children, six families with three affected, and three with four affected.

As further confirmation of the population stratification hypothesis, a replication material consisting of 148 singleaffected families (family set 2) was analysed in the TDT study. Ninety-three of these had a female proband and 55 a male proband. Only families in which at least one parent originated from southwest Sweden and with two unaffected parents and one affected child were used in the TDT study.

\section{DNA Extraction, PCR Conditions and Analyses of Amplified Products}

Genomic DNA extraction from $10 \mathrm{ml}$ venous blood samples anticoagulated with EDTA was performed using standard phenol-chloroform procedures. ${ }^{27}$ Primer sequences for polymorphic microsatellite markers were obtained from the Généthon (http://www.genethon.fr/), CHLC (http:/ /www.chlc.org/) and GDB (http://www.gdb.org) databases and synthesised on an ABI 392 DNA/RNA Synthesizer (PE Biosystems, Foster City, CA). PCR reactions were performed according to standard procedures in a total volume of $20 \mu \mathrm{l}$ with $125 \mathrm{ng}$ genomic DNA and $20 \mathrm{pmol}$ of each primer, using $\alpha^{32}$ P-dCTP (Amersham Pharmacia Biotech, Uppsala, Sweden) for radioactive labeling of PCR products. PCR products were resolved on a $6 \%$ denaturing polyacrylamid $/ 7 \mathrm{M}$ urea gel. All reactions were performed on 96-well microtiter plates.

Genotypes in the TDT study were determined on an ABI 377 (PE Biosystems) using fluorescence labelled markers. Each forward primer was 5'-tailed with an M13 sequence 5'-CGACGTTGTAAAACGACGGCCAGT-3'. The reverse primer was unmodified. A third primer, based on M13 sequence 5'-end (Amersham Pharmacia Biotech) and labelled with either FAM, TET or HEX, was added to the master mix. The PCR reaction was performed under the same conditions as described above, with the exception of primer concentrations: the tailed forward primer $10 \mathrm{pmol} / \mathrm{reaction}$, reverse primer $20 \mathrm{pmol} /$ reaction and labelled M13 primer $5 \mathrm{pmol} / \mathrm{reaction}$. The genotype for each individual was determined using GENOTYPER software (PE Biosystems).

\section{Linkage Analysis}

The preliminary pairwise linkage study was performed using the LINKAGE package. ${ }^{28}$ A recessive model with an estimated penetrance of $80 \%$ and a gene frequency of 0.25 (deduced from earlier studies, ${ }^{6,11}$ ) and a dominant model with an estimated penetrance of $70 \%$ and a gene frequency of $1.3 \%{ }^{17}$ were used.

The extension study on the chromosome 3 locus included all 104 families. In this study, we used the GENEHUNTER 1.1 software, ${ }^{29}$ which performs complete multipoint parametric and non-parametric linkage analysis.

The genetic map used in the chromosome 3 region was obtained through the Généthon ${ }^{30}$ and CHLC database (www.chlc.org/data/integratedmaps). Marker location was also determined using Stanford G3 Radiation Hybrid Panel (Research Genetics, Huntsville, AL). YAC and BAC contigs were constructed for the region.

Marker distances (in cM) used in the study on chromosome 3 were: centromere - D3S2460 - (1.5) - D3S1267 - (0.6) D3S3552 - (0.5) - D3S1269 - (0.6) - D3S1551 - (0.9) D3S1765 - (0.5) - D3S2370 - (0.5) - D3S1589 - (0.5) D3S2324 - (1.6) - D3S1541 - (0.6)- D3S1587 - (1.6) D3S1292 - (2) - D3S1238 - (5) - D3S1764 - (5) - D3S1744 $\mathrm{q}-$ term. See Figure 2 for a graphic description.

\section{Transmission Disequilibrium Test (TDT)}

Family sets $1 \mathrm{C}$ and 2 were analysed in the TDT study. Each allele for every individual was size-determined and manually

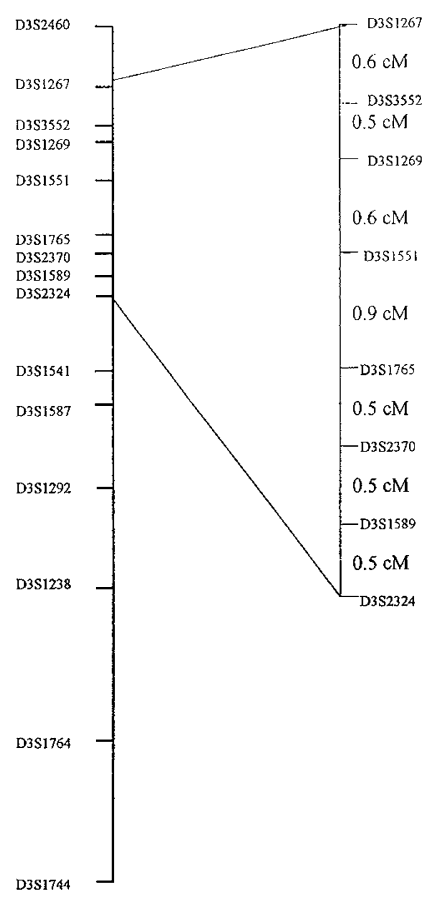

Figure 2 Detailed map of the chromosome 3 q21 region. The total size of the region D3S2460-D3S1744 is approximately $21 \mathrm{cM}(21.4)$ 
labelled with the allele number. Eight polymorphic microsatellites, D3S1267, D3S3552, D3S1269, D3S1551, D3S1765, D3S2370, D3S1589 and D3S2324, were used in the test. The transmitted/non-transmitted parental alleles were subsequently scored and the TDT was performed using the ETDT program. $^{31}$

\section{Results}

\section{Pairwise Linkage Study}

The primary pairwise linkage study consisted of a set of 20 families collected mainly from southern Sweden. We used a limited number of markers in the genome wide linkage study. A total of 168 markers on the material were analysed (average spacing $20 \mathrm{cM}$ ). Altogether, six regions with a homogeneous lod score $>0.5$ were found (recessive model $80 \%$ penetrance, $25 \%$ gene frequency). These regions were located on chromosome 2 (GAAT1A5), 3 (D3S1238), 4 (D4S194), 5 (D5S436), 14 (D14S72) and 15 (CYP19). Findings on chromosomes with earlier reported psoriasis locations such as 4, 6 and 17, have been analysed in all 104 families and are published elsewhere. ${ }^{14}$

Adjacent markers in each of the six susceptibility regions were analysed using an extended family material of 47 families (set 1A, Figure 1A). The chromosome 3 location was confirmed with an increased homogeneous lod score value of 3.36 at marker D3S1238 (recessive model). Assumption of a heterogeneous situation gave a heterogeneous lod score $($ hLOD $)=3.85(\alpha=0.45)$ at the same position $(\alpha$ being the fraction of families linking to this position). At the remaining five suggestive locations obtained in the pairwise linkage study, the lod score decreased to less than zero in the extended material (detailed data available on request).

\section{Chromosome 3q21 Location}

A total of 104 families (153 sib pairs - family set 1B) (Figure 1A) with at least two affected siblings was further analysed with markers in the chromosome 3q21 region (for map of markers see Figure 2). Non-parametric linkage (NPL) with the GENEHUNTER 1.1 software was performed. A maximum NPL value of 1.77 ( $P$ value 0.04$)$ was obtained at marker D3S1589 located approximately $6 \mathrm{cM}$ proximal to the first suggested position at marker D3S1238. A heterogeneous lod score (hLOD) using a recessive model with $80 \%$ penetrance and $25 \%$ gene frequency indicated a maximum hLOD value of $1.51(\alpha=0.14)$ at marker D3S1238. A dominant model with $70 \%$ penetrance and $1.3 \%$ gene frequency indicated a region in the vicinity of marker D3S1238 (1 cM dist.) with a maximum hLOD of $1.37(\alpha=0.25)$. NPL and hLOD results of all models used and additional analysed markers in the region are shown in Figure 3B.

\section{Population Stratification}

Place of birth of both parents in the 104 families (set 1B) were investigated (Figure 3A). Families where at least one parent was born in southwest Sweden were selected to test for a population stratification hypothesis (Figure 4A). Altogether 40 families (set 1C) (Figure 1A) were selected from the original 104 families from set $1 \mathrm{~B}$. Parametric and non-parametric linkage analysis was performed on the divided material. The

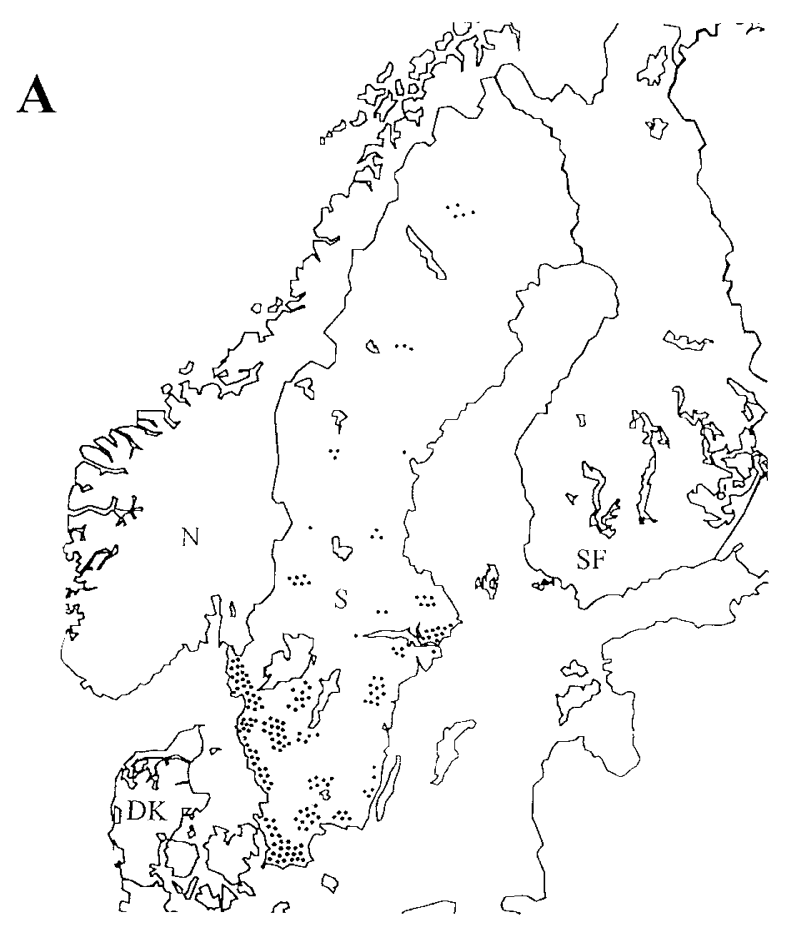

B

All 104 families (set 1B)

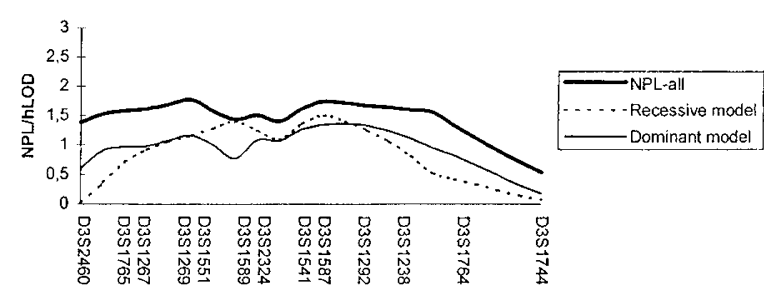

Figure 3 A Distribution of parental birthplaces in 104 families (set 1B) from Sweden used in the chromosome 3q21 study. Each dot represents one parent. B Graph of $N P L / h L O D$ values of the total material (153 sib pairs) 
NPL reached a maximum value of 2.77 ( $P$ value 0.003 ) and a maximum hLOD value of $2.59(\alpha=0.32)$ using a recessive model at marker D3S1587 (Table 1). Calculations with a dominant model suggested a region $1 \mathrm{cM}$ distal to marker D3S1587 with a maximum hLOD of $1.92(\alpha=0.44)$. Figure 4B gives a graphic view of all models with adjacent analysed markers.

\section{Linkage Disequilibrium Study}

To follow up the evidence of linkage in the chromosome 3q21 region, the material was analysed for potential founder effects with TDT. Each member of

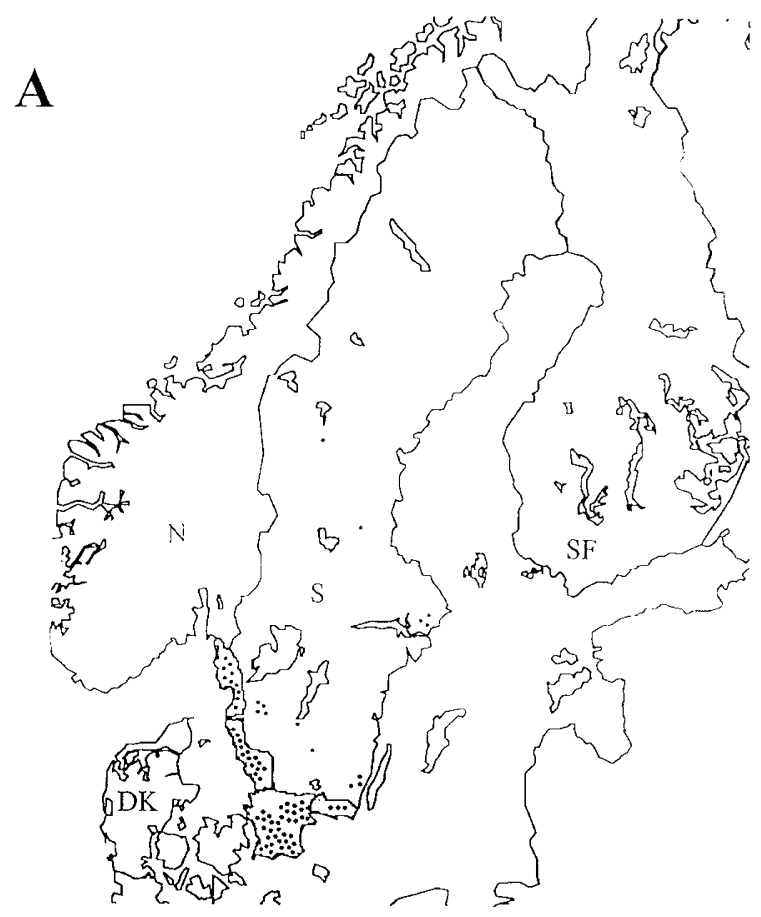

B

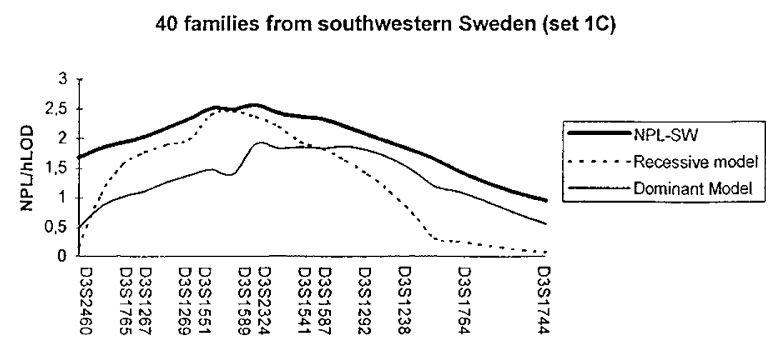

Figure 4 A Distribution of parental birthplaces in 40 families (set 1C) from Sweden used in the TDT study. Each dot represents one parent. The shaded area show southwest Sweden, where 148 families (set 2) were collected for the replication TDT study. B Graph of NPL/hLOD values on the stratified material
Table 1 Result of linkage analysis using GENEHUNTER 1.1 on chromosome 3 q21. Forty multiple-affected families (set 1C) who originate from southwest Sweden were analysed

\begin{tabular}{llll}
\hline Locus & $\begin{array}{l}\text { (hLOD, } \\
\text { alpha })\end{array}$ & $\begin{array}{l}\text { NPL score, } \\
\text { P-value }\end{array}$ & $\begin{array}{l}\text { Information } \\
\text { content }\end{array}$ \\
\hline D3S2460 & 0.166, a 0.105 & $1.682,0.048$ & 0.866 \\
D3S1551 & $1,688,0.238$ & $1.940,0.027$ & 0.876 \\
D3S1589 & $2.000,0.263$ & $2.338,0.010$ & 0.967 \\
D3S2324 & $2.462,0.295$ & $2.542,0.006$ & 0.967 \\
D3S1541 & $2.463,0.303$ & $2.499,0.007$ & 0.912 \\
D3S1587 & $2.588,0.320$ & $2.766,0.003$ & 0.920 \\
D3S1292 & $2.207,0.301$ & $2.441,0.008$ & 0.879 \\
D3S1238 & $1.822,0.259$ & $2.335,0.010$ & 0.931 \\
D3S1764 & $0.306,0.125$ & $1.652,0.051$ & 0.914 \\
D3S1744 & $0.072,0.064$ & $0.952,0.169$ & 0.814
\end{tabular}

${ }^{\mathrm{a}}$ Maximum lod scores, obtained with the best model (recessive $80 \%$ penetrance, $25 \%$ gene frequency), are presented as heterogeneous scores (hLOD).

the 40 families (set 1C) who originated from southwest region was haplotyped. The non-transmitted alleles of the unaffected parents were used as controls (association study with internal controls). Both alleles in the affected sib were scored as affected. Markers, D3S1267, D3S3552, D3S1269, D3S1551, D3S1765, D3S2370, D3S1589 and D3S2324 were used in the specific linkage disequilibrium study. Markers D3S1269 ( $P$ value 0.005$)$, D3S3552 $(P$ value 0.026$)$ and D3S1765 ( $P$ value 0.039$)$ indicated an allele distribution deviating from random, which resulted in a significant $P$ values $(<0.05)$ in this set $1 \mathrm{C}$ (see Table 2 for details).

A replicate TDT on an independent family set 2 (Figure 1B) from southwest Sweden consisting of 148 single-affected families collected with the same criteria as above was performed. The same eight markers as described previously were used. Markers D3S3552 ( $P$ value 0.015$)$ and D3S1551 ( $P$ value 0.0007$)$ showed significance in this set. The two sets were also analysed together. Four out of eight markers showed significant $P$ values in the combined sets (all data are shown in Table 2).

\section{Discussion}

Like several other diseases with suggested complex inheritance, psoriasis has been subjected to genome wide scans. ${ }^{12,13,16-18}$ A few locations have been replicated, whilst some groups have presented loci not found by others. The discrepancy regarding psoriasis susceptibility gene locations in different investigations could be due to differences in the family material used in the different studies. Two loci have been replicated 
Table 2 TDT results in the region of chromosome $3 \mathrm{q} 21$ region of two independent sets of family material (1C and 2), where at least one parent/family is born in southwest Sweden

\begin{tabular}{|c|c|c|c|}
\hline Marker & $\begin{array}{l}\text { No. } \\
\text { alleles }\end{array}$ & Family set & $\begin{array}{l}\text { TDT results } \\
P \text {-value }\end{array}$ \\
\hline \multirow{3}{*}{ D3S1267 } & \multirow[t]{3}{*}{17} & 40 families $^{\mathrm{a}}$ & 0.080 \\
\hline & & 148 families $^{\mathrm{b}}$ & 0.467 \\
\hline & & Total & 0.360 \\
\hline \multirow[t]{3}{*}{ D3S3552 } & \multirow[t]{3}{*}{8} & 40 families & 0.026 \\
\hline & & 148 families $^{b}$ & 0.015 \\
\hline & & Total & 0.0038 \\
\hline \multirow[t]{3}{*}{ D3S1269 } & \multirow[t]{3}{*}{10} & 40 families $^{\mathrm{a}}$ & 0.005 \\
\hline & & 148 families & 0.183 \\
\hline & & Total & 0.0041 \\
\hline \multirow[t]{3}{*}{ D3S1551 } & \multirow[t]{3}{*}{11} & 40 families $^{\mathrm{a}}$ & 0.615 \\
\hline & & 148 families $^{\mathrm{b}}$ & 0.0007 \\
\hline & & Total & 0.025 \\
\hline \multirow[t]{3}{*}{ D3S1765 } & \multirow[t]{3}{*}{5} & 40 families $^{\mathrm{a}}$ & 0.039 \\
\hline & & 148 families $^{\mathrm{b}}$ & 0.662 \\
\hline & & Total & 0.053 \\
\hline \multirow[t]{3}{*}{ D3S2370 } & \multirow[t]{3}{*}{5} & 40 families $^{\mathrm{a}}$ & 0.943 \\
\hline & & 148 families $^{b}$ & 0.930 \\
\hline & & Total & 0.938 \\
\hline \multirow[t]{3}{*}{ D3S1589 } & \multirow[t]{3}{*}{9} & 40 families & 0.247 \\
\hline & & 148 families $^{b}$ & 0.077 \\
\hline & & Total & 0.012 \\
\hline \multirow[t]{3}{*}{ D3S2324 } & \multirow[t]{3}{*}{4} & 40 families ${ }^{\mathrm{a}}$ & 0.168 \\
\hline & & 148 families & 0.232 \\
\hline & & Total & 0.649 \\
\hline
\end{tabular}

${ }^{4} 40$ multiply affected families from the southwestern part of Sweden used in the original study (set 1C).

b148 singly affected families from the southwestern part of Sweden used in the replication TDT study (set 2).

by several groups, ie the HLA region on chromosome $6^{13,14,16,23-25}$ and the region on chromosome 17q. ${ }^{12-14}$

We present here evidence for a psoriasis susceptibility locus in the chromosome region $3 \mathrm{q} 21$ identified in stratified patient material from Sweden. First, a pairwise linkage study was performed on limited family material optimised for recessive genes by using two unaffected parents with both affected and unaffected siblings. All peak regions (lod score values $>0.5$ ) obtained in the first scan were further investigated with additional families. Scanning the genome with a few families to identify susceptibility regions has been suggested as an efficient first strategy in genome scanning projects, ${ }^{32}$ but a dense genome scan using 86 of these families from set $1 \mathrm{~B}$ is also in progress. Results from this dense genome scan are congruent with the results presented here on chromosome 3q21 (unpublished data). In this study an early indication of linkage was obtained at chromosome $3 q 21$. The preliminary family set was extended with families fitting our criteria for recessive inheritance. Collection of blood samples started in southwest Sweden and gradually extended to the east and north. We found that adding new families increased the lod score at the chromosome $3 q 21$ location, thereby confirming the preliminary findings, up to the point when families from other parts of Sweden (east and north) were added to the data. Therefore, we suspected that a geographically distributed psoriasis susceptibility gene existed, enriched in the population living in southwest Sweden today.

The population stratification hypothesis was tested in an association study. Families originating from southwest Sweden (set 1C) and an independent family set of 148 singly affected families (set 2 ) were analysed in a TDT study. The result confirmed our theory of the existence of a potential founder mutation in the vicinity of marker D3S3552. The region, including markers D3S3552-D3S1551 (spanning approximately $1 \mathrm{cM}$ ), gave a significant $P$ value in the combined material even when taking into account levels in significant $P$ values due to multiple testing.

It is likely that the southern and middle parts of Sweden became inhabited from the south, resulting in a mutation spectrum over the country. There are several examples of mutation spectra for genetic disorders that vary within Sweden, eg in carbohydrate deficient glycoprotein syndrome (CDG1A). ${ }^{33}$ Southwest Sweden belonged to the Danish Kingdom from medieval times until the 17 th century. It is therefore likely that the southwestern Swedish and Danish populations have a similar genetic background. A similar study on Danish psoriasis patient material could therefore be interesting.

In summary, we have identified a highly interesting psoriasis susceptibility region in the vicinity of markers D3S1551 and D3S3552 at chromosome 3q21, by working with a population stratification hypothesis among the Swedish population. The chromosome $3 \mathrm{q} 21$ region contains mostly unidentified transcripts with no obvious psoriasis gene candidate. In a recent genome scan study performed by Cornelius et $a l^{34}$ searching for susceptibility regions in rheumatoid arthritis (RA) the same chromosomal region on $3 \mathrm{q} 21$ as presented here was implicated. Interestingly, psoriasis has long been known to be associated with joint-related problems like psoriatic arthritis. At this stage one can only speculate on a possible similar genesis for rheumatoid arthritis and psoriasis, both considered as autoimmune disorders.

Future perspectives suggest linkage disequilibrium studies on single nucleotide polymorphism (SNP) in the 
chromosome $3 \mathrm{q} 21$ region to narrow down the suggested region further. Such a study has been initiated.

\section{Acknowledgements}

We are grateful for the financial support of the Swedish Psoriasis Association, the Welander Foundation, the Swedish Medical Research Council (project no B96-19X-11246-02B) and Glaxo-Wellcome Research and Development Ltd.

\section{References}

1 Lomholt G: Psoriasis: Prevalence, spontaneous course and genetics: a census study on the prevelance of skin disease on the Faroe Islands. GEC Gad: Copenhagen, 1963.

2 Hellgren L: Psoriasis: the prevalence of sex, age and occupational groups in total populations in Sweden. Morphology, inheritance associations with other skin and rheumatic diseases. Almquist \& Wiksell: Stockholm, 1967.

3 Barisic-Drusko V, Dobric I, Pasic A et al: Frequency of psoriatic arthritis in general population and among the psoriatics in Department of Dermatology. Acta Derm Venereol Suppl Stockh 1994; 186: 107-108.

4 Salvarani C, Lo-Scocco G, Macchioni P et al: Prevalence of psoriatic arthritis in Italian psoriatic patients. $J$ Rheumatol 1995; 22: 1499-1503.

5 Henseler T, Christophers E: Psoriasis of early and late onset: Characterization of two types of psoriasis vulgaris. J Am Acad Dermatol 1985; 13: 450-456.

6 Swanbeck G, Inerot A, Martinsson T et al: Age at onset and different types of psoriasis. Br J Dermatol 1995; 133: 768-773

7 Abele D, Dobson R, Graham J, Hill C: Heredity and psoriasis: study of a large family. Arch Dermatol 1963; 88: 89-99.

8 Watson W, Cann HM, Farber EM, Nall ML: The genetics of psoriasis. Arch Dermatol 1972; 105: 197-207.

9 Nair RP, Guo S-W, Jenisch S et al: Scanning chromosome 17 for psoriasis susceptibility: Lack of evidence for a distal 17q locus. Hum Hered 1995; 45: 219-230.

10 Iselius L, Williams WR: The mode of inheritance of psoriasis: Evidence for a major gene as well as a multifactorial component and its implication for genetic counseling. Hum Genet 1984; 68: 73-76.

11 Swanbeck G, Inerot A, Martinsson T, Wahlström J: A population genetic study of psoriasis. Br J Dermatol 1994; 131: 32-39.

12 Tomfohrde J, Silverman A, Barnes R et al: Gene for familiar psoriasis susceptibility mapped to the distal end of human chromosome 17q. Science 1994; 264: 1141-1145.

13 Nair RP, Henseler T, Jenisch S et al: Evidence for two psoriasis susceptibility loci (HLA and 17q) and two novel candidate regions $(16 \mathrm{q}$ and $20 \mathrm{p})$ by genome-wide scan. Hum Mol Genet 1997; 8: 1349-1356.
14 Enlund F, Samuelsson L, Enerbäck C et al: Analysis of three suggested psoriasis susceptibility loci in a large Swedish set of families; confirmation of linkage to chromosome 6p (HLA-region), and to $17 \mathrm{q}$, but not to $4 \mathrm{q}$. Hum Hered 1999; 49: 2-8.

15 Matthews D, Fry L, Powles A, Weissenbach J, Williamson $\mathrm{R}$ : Confirmation of genetic heterogeneity in familial psoriasis. J Med Genet 1995; 2: 546-548.

16 Trembath RC, Clough RL, Rosbotham JL et al: Identification of a major susceptibility locus on chromosome $6 p$ and evidence for further disease loci revealed by a two stage genome-wide search in psoriasis. Hum Mol Genet 1997; 6 : 813-820.

17 Matthews D, Fry L, Powles A et al: Evidence that a locus for familial psoriasis maps to chromosome 4q. Nat Genet 1996; 14: 231-233.

18 Capon F, Novelli G, Semprini S et al: Searching for psoriasis susceptibility genes in Italy: Genome scan and evidence for a new locus on chromosome 1. J Invest Dermatol 1999; 112: 32-35.

19 Tiilikainen A, Lassus A, Karvonen J, Vartiainen P, Julin M: Psoriasis and HLA-Cw6. $B r \quad J$ Dermatol 1980; 102: 179-183.

20 Elder JT, Henseler T, Christophers E, Voorhees JJ, Nair RP: Of genes and antigens: The inheritance of psoriasis. $J$ Invest Dermatol 1994; 103: 150S-153S

21 Enerbäck C, Martinsson T, Inerot A et al: Evidence that HLA-Cw6 determines early onset of psoriasis - obtained using sequence-specific primers (PCR-SSP). Acta Dermatol Venerol 1997; 77: 273-276.

22 Enerbäck C, Martinsson T, Inerot A et al: Significantly earlier age at onset for the HLA-Cw6-positive than for the Cw6-negative psoriatic sibling. J Invest Dermatol 1997; 22: 695-696.

23 Burden AD, Javed S, Bailey $\mathrm{M}$ et al: Genetics of psoriasis: paternal inheritance and a locus on chromosome $6 \mathrm{p} . J$ Invest Dermatol 1998; 110: 958-960.

24 Jenisch S, Henseler T, Nair RP et al: Linkage analysis of human leukocyte antigen (HLA) markers in familial psoriasis: strong disequilibrium effects provide evidence for a major determinant in HLA-B/C Region. Am J Hum Genet 1998; 63: 191-199.

25 Leder RO, Mansbridge JN, Hallmayer J, Hodge SE: Familial psoriasis and HLA-B: Unambiguous support for linkage in 97 published families. Hum Hered 1998; 48 198-211.

26 Spielman R, McGinnis RE, Ewenst WJ: Transmission test for linkage disequilibrium: The insulin gene region and insulin-dependent diabetes mellitus (IDDM). Am J Hum Genet 1993; 52: 506-516.

27 Ausubel FM: Current protocols in molecular biology. In: Brent R, Kingston RE, Moore DD, Seidman JG, Smith JA, Struhl K (eds). Wiley Interscience: New York, 1995.

28 Lathrop GM, Laouel JM: Fast calculations of LOD scores and genetic risks on small computers. Am J Hum Genet 1984; 36: 460-465.

29 Kruglyak L, Daly M, Reeve-Daly M, Lander E: Parametric and nonparametric linkage analysis: a unified multipoint approach. Am J Hum Genet 1996; 58 1347-1363. 
30 Dib C, Fauré S, Fizames C et al: A comprehensive genetic map of the human genome based on 5,264 microsatellites. Nature 1996; 380: 152-154.

31 Sham PC, Curtis D: An extended transmission/disequilibrium test (TDT) for multi-allele marker loci. Ann Hum Genet 1995; 59: 323-326.

32 Holmans P, Craddock N: Efficient strategies for genome scanning using maximum-likelihood affected-sib-pair analysis. Am J Hum Genet 1997; 60: 657-666.
33 Bjursell C, Stibler H, Wahlström J et al: Fine mapping of the gene for carbohydrate-deficient glycoprotein syndrome, type I (CDG1): Linkage disequilibrium and founder effect in Scandinavian families. Genomics 1997; 39: 247-253.

34 Cornelis F, Fauré S, Martinez M et al: New susceptibility locus for rheumatoid arthritis suggested by a genomewide linkage study. Proc Natl Acad Sci USA 1998; 95: 10746-10750. 